\author{
Marco Mauri \\ Luisella Sibilla \\ Giorgio Bono \\ Giovanni Augusto Carlesimo \\ Elena Sinforiani \\ Adelaide Martelli
}

\section{The role of morpho-volumetric and memory correlations in the diagnosis of early Alzheimer dementia}

Received: 11 June 1997

Received in revised form: 6 February 1998 Accepted: 10 February 1998

M. Mauri · L. Sibilla $\cdot$ E. Sinforiani $(\bowtie)$ A. Martelli

I.R.C.C.S. Neurologico C. Mondino,

Via Palestro 3, I-27100 Pavia, Italy

Tel.: +39-382-3801

Fax: +39-382-380286

G. Bono

II Facoltà di Medicina, Varese, Italy

G. A. Carlesimo

I.R.C.C.S. Lucia, Rome, Italy

\begin{abstract}
The aim of the present study was to assess selective atrophy of the temporal lobe and amygdala in the early stages of Alzheimer dementia (AD). Magnetic resonance imaging (MRI) measurements and the presence of highsignal lesions (HSL) were analysed in 31 patients with mild to moderate probable $\mathrm{AD}$ and 22 controls. In the AD group, MRI findings were compared with cognitive variables and specific features of memory functions. Alzheimer patients showed a significant reduction in volumetric measurement compared with controls in the total volume $(P<0.01)$, temporal lobe $(P<0.01)$ and amygdala $(P<0.05)$. The temporal lobe/brain volume ratio was also significantly reduced in AD subjects
\end{abstract}

$(P<0.05)$. Atrophy of temporal structures was significantly related to the degree of episodic and semantic memory impairment according to a material-specific effect. No significant correlations between amygdala and cognitive variables were found. The results of our study confirm the usefulness of measures of temporal lobe atrophy assessed with MRI in the diagnosis of $\mathrm{AD}$. In contrast, HSL are relatively common in $\mathrm{AD}$ patients (12/31 cases) and were not related to volumetric findings, severity of dementia or functional disability.

Key words Alzheimer dementia . Magnetic resonance imaging • Temporal lobe $\cdot$ Amygdala $\cdot$ High signal lesions

\section{Introduction}

Despite McKhann et al. [1] and DSM IV [2] diagnostic criteria, differentiating early Alzheimer dementia (AD) from cognitive changes occurring in other non-dementing conditions such as physiological aging or depressive pseudodementia of the elderly may present some difficulties. Moreover, diagnostic criteria have not been clearly defined in other degenerative dementia of non-AD type, i.e. Pick's disease, frontal degeneration and dementia with Lewy's bodies. Biological markers in vivo of AD have, in fact, not yet been identified.

A disturbance of memory is frequently the first symptom of complaint in AD patients and is generally regarded as a necessary (but not a sufficient) clinical feature for the diagnosis $[1,2]$. Despite controversy about which struc- tures are critical for normal processes, it is widely accepted that brain damage in amnesic subjects involves the mesial temporal areas and/or portions of the diencephalon. Among these areas, the most consistently and extensively damaged in $\mathrm{AD}$ are the mesial temporal structures [3]. Volumetric measurements by magnetic resonance imaging (MRI) of the temporal lobe, amygdala and hippocampal formation have therefore been proposed [4-7]. MRI studies have confirmed the reduction of temporal lobe and hippocampal structures in AD [8-10], while in normal subjects a significant age-related decrease only of the frontal lobe, but not of the temporal one, has been found [11]. The degree of volume reduction seem to be related to disease progression.

The aim of this study was therefore to evaluate: (a) any correlation between volumetric measurements and neuropsychological parameters and (b) whether such correla- 
tions were specific for AD and could improve the diagnostic accuracy in the early stages of the disease. The cognitive evaluation, unlike other studies that have employed rough neuropsychological measures, has been aimed to accurately investigate specific aspects of declarative memory function.

\section{Patients and methods}

Patients

Thirty-one patients with a diagnosis of probable AD according to NINCDS-ADRDA [1] criteria and mild to moderate severity [Global Deterioration Scale (GDS) $=4-5$; Mini Mental State (MMS) ranged from 14 to 23] $[12,13]$ were recruited.

No vascular risk factors or symptomatic vascular disease (heart disease, stroke or TIA, history of syncope, focal neurological signs, symptomatic orthostatic hypotension) were detected [Hachinski Ischaemic Score (HIS) 4] [14]. Severe neuropsychiatric disorders and the use of neuroleptics were also exclusion criteria. The Barthel index was used as a measure of functional disability [15]. We studied all cases consecutively observed at the Neurological Institute C. Mondino during 1996. Neurological, neuropsychological and neuroradiological investigations were carried out. MRI was performed in the same week as the neuropsychological evaluation.

Twenty-two subjects were selected as a control group. Their distribution for decades, sex and education was similar to the AD group. Controls were recruited from inpatients referred to our neurological institute for neurological disorders not involving the central nervous system such as peripheral nerve entrapment, lumbosacral pain or sciatica. None had a history of head trauma, alcohol abuse or symptomatic vascular disease. No previous central neurological or psychiatric diseases were detected. The MMS score was > 24 and the neurological examination excluded central signs. All patients and controls were right-handed according to the

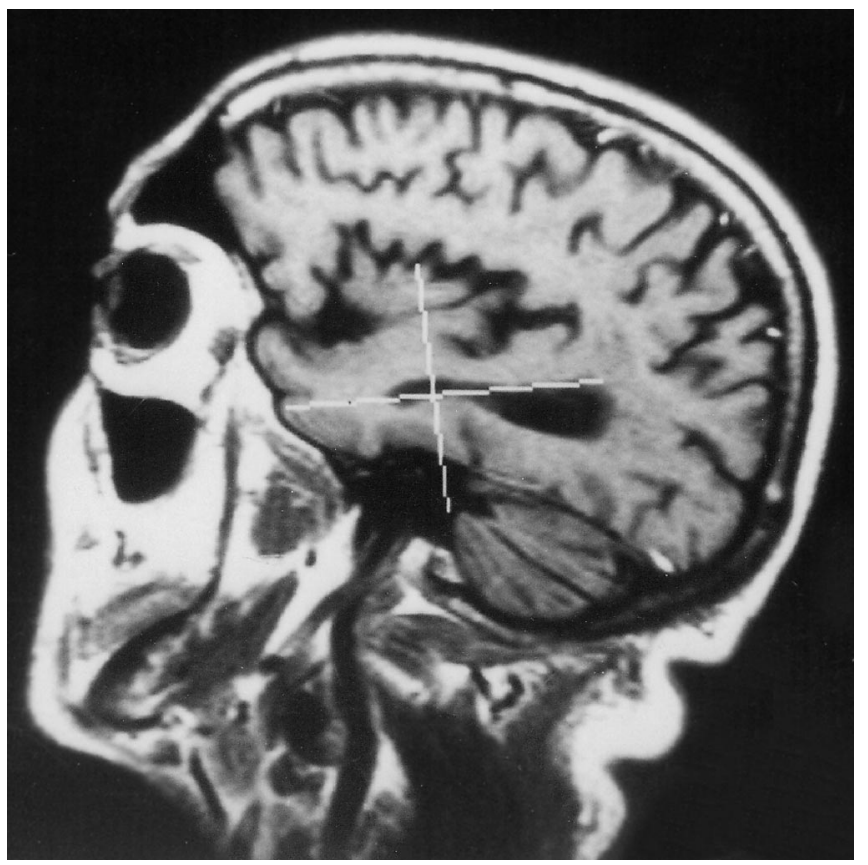

Fig. 1 Sagittal T1-weighted image for the determination of the long axis of the temporal lobe
Oldfield questionnaire [16]. Informed consent was obtained by each subject included in the study.

\section{Methods}

\section{Neuroradiological investigation}

MRI was performed with a 0.5-T superconducting magnet (Philips Gyroscan T5). Sagittal T1-weighted images (SE, $5 \mathrm{~mm}$ thick, $2.5 \mathrm{~mm}$ gap, TR 520, TE 20, NSA 1) and T2-weighted scans (SE, $7 \mathrm{~mm}$ thick, $0.7 \mathrm{~mm}$ gap, TE 2500, TE 40/100, NSA 1) were first obtained to determine the long axis of the temporal lobe and to exclude major cerebral infarction (Fig. 1). A sequence of 128 coronal oblique T1-weighted fast-field-echo images perpendicular to the long axis of the temporal lobe was performed to measure the volume of brain, temporal lobe and amygdala (TR 33, TE 13, FA 30, $1.5 \mathrm{~mm}$ thick, overcontiguous, NSA 2).

Image processing: The images were transferred to a SUN Gyroview-HR workstation and analsed with a CAMRA S400 Allegro application by ISG Technology Inc. through three steps:

1. Identification and storage of window width and level

2. Segmentation techniques that include region-growing from seed point to isolate objects of similar intensities and gradientbased edge-tracking for complex contours

3. Automatic volumetric reconstruction
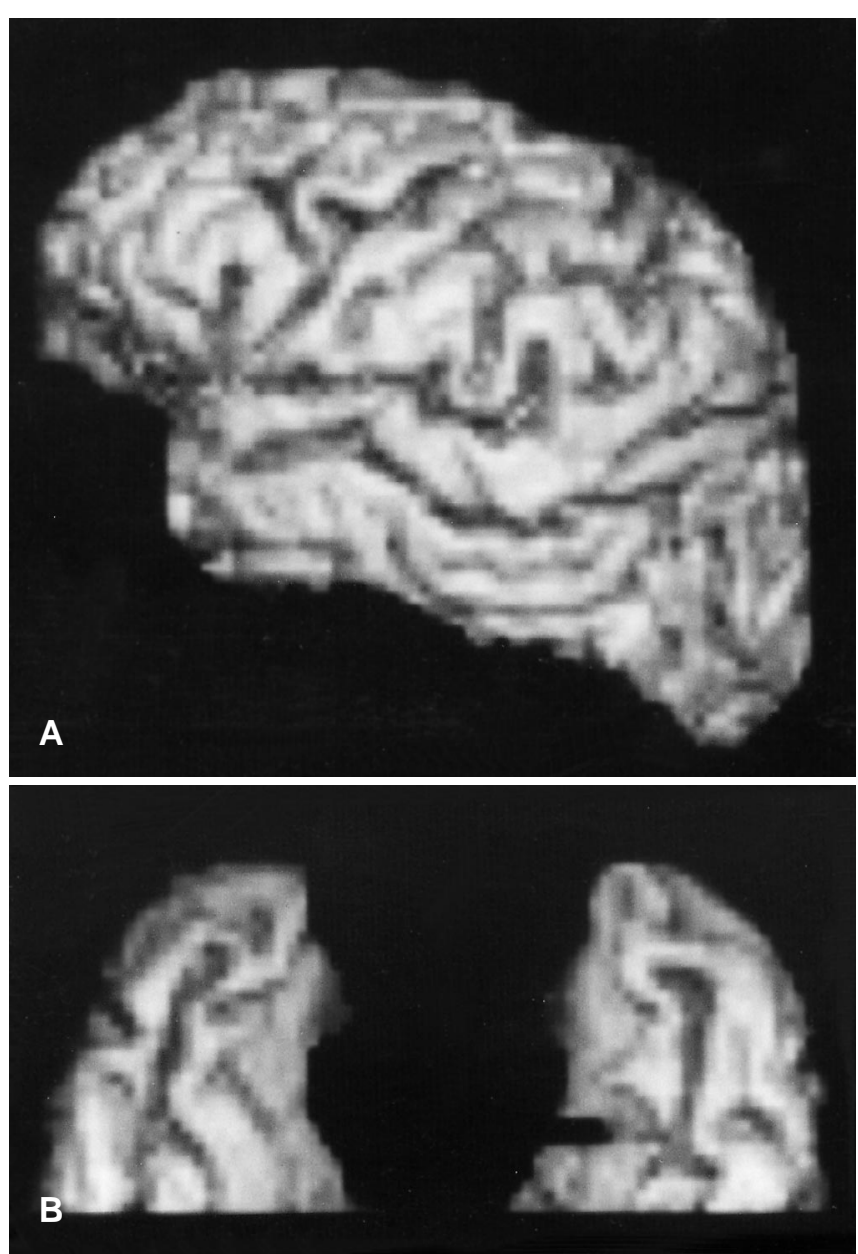

Fig. 2 A, B Three-dimensional reconstruction of the brain: (A) lateral view, (B) temporal lobes, axial view 


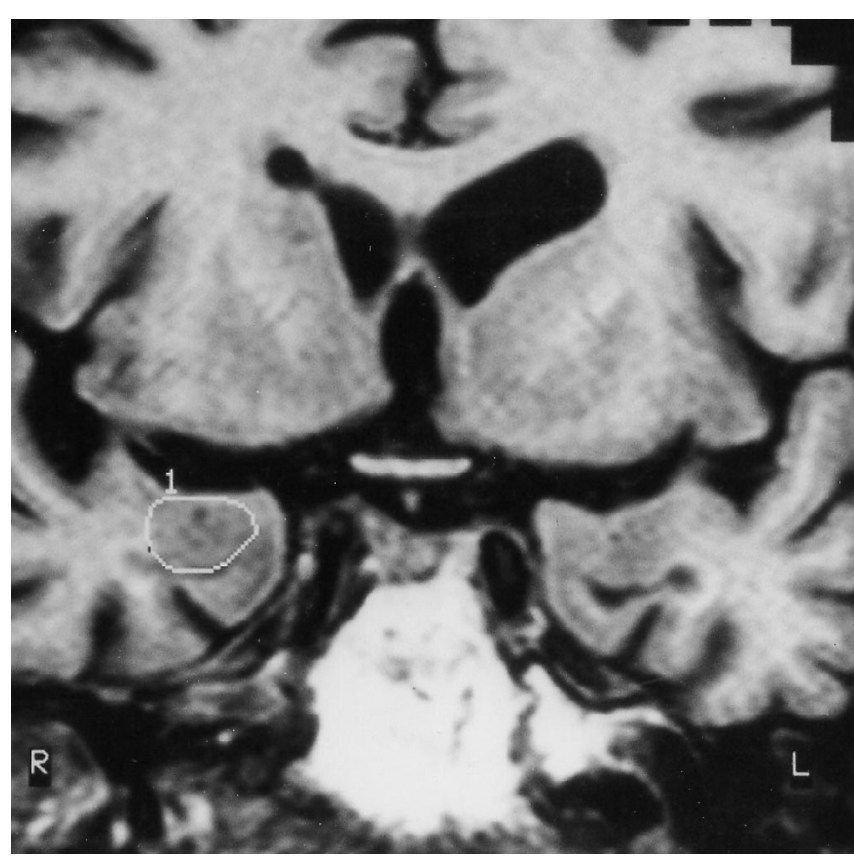

Fig. 3 Boundaries of the amygdala determined on magnetic resonance imaging coronal oblique slice

Brain temporal lobes and amygdala, except brain stem and cerebellum, were reconstructed (Fig. 2A, B). The posterior boundary for the temporal lobes was defined by the oblique coronal plane intersecting the posterior commissure and the anterior boundary by the most anterior slice of the temporal lobe. The anatomical guidelines for the amygdala were fixed according to a temporal lobe antomy atlas (Fig. 3) [17].

Volumes were measured in cubic centimetres as absulute volume, and for the temporal lobes and amygdala also as percentage of total brain volume in order to minimize the effect of interindividual variation in head size. For temporal lobe and amygdala, the volume is the sum of both sides.

Measurements were performed separately by two operators experienced in the procedure and blinded to clinical and neuropsychological information. In order to evaluate the reproducibility of the volume measurements, a second evalutaion was performed after 1 month. The correlation coefficient between the two readings ranged from 0.92 to 0.97 for all measurement, indicating a good level of reliability. We used the mean of the two volumetric measurements in the final analysis. The extent of high signal lesions (HSL) such as subcortical white matter lesions (WML) and periventricular hyperintensities (PHV) was also recorded. Ratings, based on the proton density images, of PVH were made on a four point scale: $0=$ absent, 1 = pencil-thin lining or "caps" at the tips of lateral ventricles, $2=$ thick lining, $4=$ large confluence around the ventricles extending throughout the centrum semiovale with irregular edges [18].

\section{Neuropsychological assessment}

The neuropsychological tests, given to all $\mathrm{AD}$ patients, are listed below. Cut-off scores for tests were set to the 5th centile of normal population scores, adjusted for age, education and, when appropriate, sex $[19,20]$. All of the tests were performed by two trained neuropsychologists:

1. Short-term memory

a) Word Span (verbal): Corsi's Block Tapping Test (visuo-spatial [19] b) Visual memory: Immediate Visual Memory Test (IVM) (recognition) [21]

2. Long-term explicit memory

a) Episodic: Rey's 15 words (verbal learning and delayed recall) [21]

Visuo-spatial supra-span learning Corsi's Block Tapping Test [19]

b) Semantic: The vocabulary subtest from the Italian version of the Wechsler Adult Intelligence Scale (WAIS) [22]

3. Verbal attainments

a) Word fluency (FAS) [21]

b) Phrase construction [21]

4. Visuo-spatial intelligence

Raven's coloured progressive matrices (PM) [21]

5. Constructive functions

Copying design: simple copy (SC) and with landmarks [21]

\section{Statistical analysis}

The demographic, volumetric and neuropsychological measures were compared using the Mann-Whitney U test and the chi-square test. Simple regression analyses $(r)$ were performed between age, psychometric performances (corrected scores) and volumetric measures. Statistical significance was taken at $P<0.05$.

\section{Results}

Table 1 summarises the main demographic characteristics. The two groups, AD and controls, did not significantly differ in age, sex, distribution and education.

Alzheimer patients showed significant reduction in volumetric measurements compared with controls consid-

Table 1 Demographic variables of AD patients and control group ( $A D$ Alzheimer dementia, MMS Mini Mental State, GDS Global Deterioration Scale)

\begin{tabular}{lll}
\hline & AD & Controls \\
\hline$n$ & 31 & 22 \\
Sex (M/F) & $13 / 18$ & $10 / 12$ \\
Age (years) (SD) & $68(6.8)$ & $67.7(7.9)$ \\
& $(58-82)$ & $(55-80)$ \\
Education (years) (SD) & $7.5(2.4)$ & $7.8(3.2)$ \\
& $(5-13)$ & $(5-13)$ \\
MMS (SD) & $17.2(3.2)$ & $28.8(1.1)$ \\
& $(14-23)$ & $(25-30)$ \\
Arterial hypertension & 5 & 3 \\
Ischaemic score (SD) & $1.3(0.5)$ & - \\
& $(0-3)$ & \\
Degree of dementia (GDS) & & - \\
$\quad$ Mild & 17 & \\
$\quad$ Moderate & 14 & \\
Duration of dementia (months) (SD) & $25(8)$ \\
& $(8-35)$ & \\
\hline
\end{tabular}




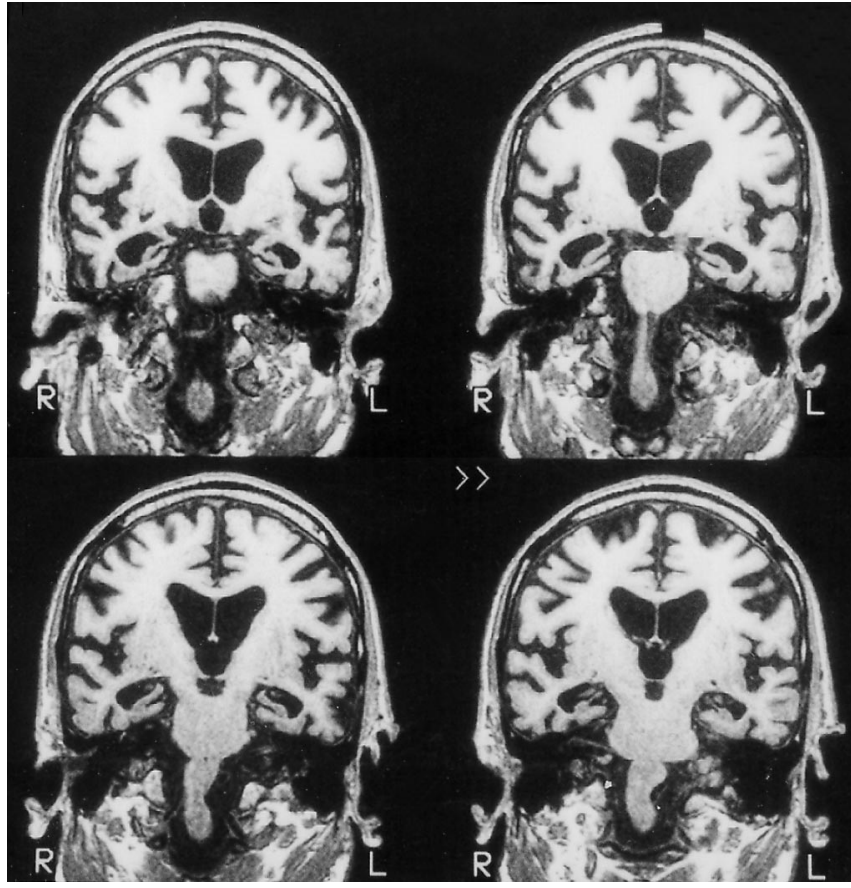

Fig. 4 Coronal T1-weighted images of the temporal lobes: severe temporal lobe atrophy in a patient with Alzheimer dementia

ering the total volume, temporal lobe $(P<0.05)$ and amygdala $(P<0.05)$ (Fig. 4$)$. The temporal lobe/brain volume ratio was also significantly reduced in AD subjects $(P<0.05)$ (Table 2$)$. AD patients had greater atrophy than controls for all measurements but, with respect to age, the slope of regression was not different between patients and controls (total volume: AD $r=20$, controls $r=18$; temporal lobe: $\mathrm{AD} r=25$, control $r=21$ ).

PVH scores were equal to $0-1$ in $19 / 31$ AD patients $(61 \%)$ to 2 in $12 / 31$ subjects $(39 \%)$. The presence of mild to moderate WML was significantly associated with PVH: 7/12 patients (58\%) with grade $2 \mathrm{PVH}$ and WML compared with only $3 / 19$ patients $(15 \%)$ with less prominent PVH (chi-square test $P<0.05$ ). In 5/22 control subjects $(23 \%)$, a PVH score equal to 2 was also detectable (chi-square test not significant vs AD).
Neuropsychological performances of AD are shown in Table 3. Several cognitive areas were affected, in particular long-term episodic and semantic memory.

No significant difference among demographic variables, functional disability, volumetric measurement and cognitive dysfunction was detectable between the two PVH groups (Tables 2, 3).

Finally, volumetric variables of 31 AD patients were compared with their cognitive performances. The analysis revealed a significant correlation between temporal lobe atrophy and degree of memory impairment: Rey's 15 words (verbal learning $r=56, P<0.01$; delayed recall $r=$ $47, P<0.01$ and WAIS vocabulary $(r=51, P<0.01)$ with left temporal lobe, visuo-spatial supra-span learning with right temporal lobe $(r=42, P<0.05)$. No significant correlations were found between memory measures and amygdala volume.

\section{Discussion}

The neuropathological changes of $\mathrm{AD}$ involve several cortical and subcortical structures characterised by diffuse neuronal loss, senile plaques and neurofibrillary tangles. Such pervasive damage is responsible for the various cognitive deficits exhibited by AD patients. The mesial temporal structures are severly compromised, and most of the neurons that normally make wide connections between the hippocampus and multiple cortical and subcortical areas are affected [23].

The abnormalities of temporal lobes and hippocampus can be related to pervasive deficits of explicit memory, which is one of the hallmarks of the disease, especially in the early stages. Memory in fact is not a unitary function, but consists of several different interacting systems subserved by different anatomical regions [24, 25]. In our study, we investigated short-term and long-term memory, which in turn includes episodic and semantic memory. Measures for each memory subsystem were administered and material-specific effects (verbal/visuo-spatial) were also considered.

The results of this study confirm, using MRI volumetric measurements, the involvement of temporal structures
Table 2 Volumetric magnetic resonance imaging analysis (cubic centimetres) in AD patients $(\mathrm{PVH}+$ and $\mathrm{PVH}-$ ) and controls [mean (SD)] $(P V H$ periventricular hypertensities, $B V$ brain volume)

$* P<0.05$, ** $P<0.01$ (AD vs controls)

\begin{tabular}{lccccccccc}
\hline & $\begin{array}{l}\text { AD } \\
(n=31)\end{array}$ & \multicolumn{3}{c}{$\begin{array}{l}\text { PVH- } \\
(n=19)\end{array}$} & $\begin{array}{l}\text { PVH+ } \\
(n=12)\end{array}$ & \multicolumn{3}{c}{$\begin{array}{l}\text { Controls } \\
(n=22)\end{array}$} \\
\hline BV & 826 & $(59.8)^{* *}$ & 821 & $(39)$ & 829 & $(55)$ & 922 & $(46.3)$ \\
Temporal lobe & 104 & $(16.5)^{* *}$ & 101 & $(14.0)$ & 106 & $(13.1)$ & 125 & $(13.4)$ \\
$\quad$ Left & 54.2 & $(9.0)^{* *}$ & 53.1 & $(7.8)$ & 54.5 & $(8.5)$ & 64.3 & $(9.1)$ \\
$\quad$ Right & 49.8 & $(8.8)^{* *}$ & 48.4 & $(9.0)$ & 51.6 & $(8.1)$ & 60.8 & $(8.2)$ \\
Temporal lobe/BV & 12.5 & $(1.7)^{*}$ & 12.3 & $(1.5)$ & 1.27 & $(1.6)$ & 13.8 & $(1.9)$ \\
Amygdala & 1.23 & $(0.4)^{*}$ & 1.22 & $(0.4)$ & 1.25 & $(0.3)$ & 1.45 & $(0.3)$ \\
Amygdala/BV & 0.15 & $(0.06)$ & 0.16 & $(0.05)$ & 0.15 & $(0.04)$ & 0.16 & $(0.05)$ \\
\hline
\end{tabular}


Table 3 Neuropsychological measures in $\mathrm{AD}$ patients $(I V M$ immediate visual memory test, WAIS Wechsler Adult Intelligence Scale, $S C$ single copy, $C L$ copy with landmarks)

\begin{tabular}{|c|c|c|c|c|c|}
\hline & \multirow[t]{2}{*}{$\begin{array}{l}\text { AD score } \\
{[\text { mean }(\mathrm{SD})]}\end{array}$} & \multirow{2}{*}{$\begin{array}{l}\text { Lower limit } \\
\text { of tolerance } \\
\text { interval }\end{array}$} & $\begin{array}{l}\mathrm{AD} \\
(n=31)\end{array}$ & $\begin{array}{l}\text { PVH- } \\
(n=19)\end{array}$ & $\begin{array}{l}\text { PVH+ } \\
(n=12)\end{array}$ \\
\hline & & & \multicolumn{3}{|c|}{ [Patients impaired $(n)]$} \\
\hline Word span & $3.7 \quad(0.8)$ & 3 & 3 & 2 & 1 \\
\hline Corsi span & $3.8 \quad(1.0)$ & 3.75 & 9 & 5 & 4 \\
\hline Corsi supra-span & $2.1 \quad(3.7)$ & 5.75 & 29 & 17 & 12 \\
\hline IVM & $14.5 \quad(2.8)$ & 13.85 & 10 & 6 & 4 \\
\hline $\begin{array}{l}\text { Rey's } 15 \text { words } \\
\text { Learning } \\
\text { Recall }\end{array}$ & $\begin{array}{cl}16 & (5.6) \\
1.1 & (2)\end{array}$ & $\begin{array}{r}28.53 \\
4.69\end{array}$ & $\begin{array}{l}30 \\
28\end{array}$ & $\begin{array}{l}18 \\
17\end{array}$ & $\begin{array}{l}12 \\
11\end{array}$ \\
\hline WAIS vocabulary & $30.1(15.6)$ & 18 & 18 & 10 & 8 \\
\hline Word fluency & $9.4 \quad(3.4)$ & 17.35 & 15 & 9 & 6 \\
\hline Phrase construction & $7.9 \quad(2.3)$ & 8.72 & 12 & 7 & 5 \\
\hline Raven's matrices & 15.1 & 18.96 & 13 & 8 & 5 \\
\hline \multicolumn{6}{|l|}{ Copying design } \\
\hline $\mathrm{SC}$ & $6.7 \quad(1.2)$ & 7.18 & 15 & 9 & 6 \\
\hline CL & $60.2 \quad(2.7)$ & 61.85 & 13 & 8 & 5 \\
\hline
\end{tabular}

and amygdala by comparing a selected group of early impaired AD patients with control subjects. The reduction of temporal lobe/brain volume ratio in AD patients supports the hypothesis that this measure is able to discriminate much more powerfully than an estimate of overall brain atrophy. Moreover, regression analysis indicated that volume loss with age was not different between the two groups.

Selective atrophy of the temporal lobes appears to be related in our patients with the degree of memory impairment. In fact, significant correlation between temporal lobes and memory measures were found; verbal learning and semantic memory deficits were related to left temporal lobe atrophy, right temporal involvement was sensible to impairment of long-term visuo-spatial memory. Memory impairment was not related to amygdala involvement. Deweer et al. [10] also did not find any correlation between anygdala volume and memory index. The authors suggested, on the basis of animal experience, that amygdala damage alone does not impair memory.
The results of our study confirm that temporal lobe atrophy assessed with MRI could be of diagnostic value in $\mathrm{AD}$, especially in the early stages of the disease. Followup studies are needed to document the temporal evolution of structural changes in relation to the rate of cognitive decline.

In about the $40 \%$ of our AD patients and $23 \%$ of the control group, periventricular high signal areas were detected. The pathophysiology and clinical relevance of these findings in AD remain controversial. In our population, these lesions were not related to volumetric measurements, severity of dementia or functional disability. The two groups in fact did not show a different pattern of cognitive involvement. According to previous data [18], the incidence of these abnormalities, if age and vascular risk factors are excluded, did not significantly differ from control patients, and their presence should not be used to preclude a diagnosis of AD.

\section{References}

1. McKhann G, Drachman D, Folstein M, Katzman R, Price D, Stadlan M (1984) Clinical diagnosis of Alzheimer's disease: report of the NINCDS-ADRDA Work Group under the auspices of the Department of Health and Human Service Task Force on Alzheimer's disease. Neurology 34 :939-942
2. American Psychiatric Association (1996) Psychiatric and statistical manual of mental disorders, 4th edn. American Psychiatric Association, Washington, DC

3. Braak H, Braak E (1991) Neuropathological staging of Alzheimer-related changes. Acta Neuropathol (Berl) 82 : 239-259
4. Watson C, Andermann F, Gloor P, et al (1992) Anatomic basis of amygdaloid and hippocampal volume measurement by magnetic resonance imaging. Neurology 42: 1743-1750 
5. Jack CR, Peterson RC, O'Brien PC, Tangalos EG (1992) MR-based hippocampal volumetry in the diagnosis of Alzheimer's disease. Neurology 42: 183-188

6. Maunoury C, Michot JL, Caillet H, et al (1966) Specifity of temporal amygdala atrophy in Alzheimer's disease: quantitative assessment with magnetic resonance imaging. Dementia $7: 10-14$

7. Kesslak JP, et al (1991) Quantification of magnetic resonance scans for hippocampal and parahippocampal atrophy in Alzheimer's disease. Neurology $41: 51-54$

8. Petersen RC, Jack CR, Smith GE, Ivnik RJ (1992) MR-based hippocampal volumes, age, duration of disease, and cognition in Alzheimer's disease. Neurology 42 [Suppl 3]: 175

9. Lehericy S, Baulac M, Chiras J, et al (1994) Amygdala and hippocampal MR volume measurements in the early stages of Alzheimer's disease. AJNR 15:927-937

10. Deweer B, Lehericy S, Pillon B, et al (1995) Memory disorders in probable Alzheimer's disease: the role of hippocampal atrophy as shown with MRI. J Neurol Neurosurg Psychiatry 58: 580-597
11. De Carli C, et al (1994) Lack of agerelated differences in temporal lobe volume of very healthy adults. AJNR $15: 689-696$

12. Reisberg B, Ferris SH, De Leon MJ, Crook T (1982) The global deterioration scale for assessment of primary degenerative dementia. Am J Psychiatry $139: 1136-1139$

13. Folstein MF, Folstein SE, McHugh PR (1975) "Mini Mental State". A practical method for grading the cognitive state of patients for the clinicians. J Psychiatr Res 12:189-198

14. Hachinski VC, Iliff LD, Zilhka E (1975) Cerebral blood flow in dementis. Arch Neurol 32:632-637

15. Mahoney F, Barthel DW (1965) A simple index of independence useful scoring improvement in the rehabilitation of chronically ill. Md Med J 6 : 493-507

16. Oldfield RC (1971) The assessment and analysis of handedness: The Edinburgh inventory. Neuropsychologica 9 : 97-113

17. Duvernoy HM (1988) The human hippocampus. An atlas of applied anatomy. Bergmann, Munich

18. Bennet DA, Gilley DW, Wilson RS, Huckman MS, Fox JH (1992) Clinical correlates of high signal lesions on magnetic resonance imaging in Alzheimer's disease. Dementia 239: 186-190

19. Spinnler H, Tognoni G (1987) Standardizzazione e Taratura Italiana di test Psicometrici. Ital J Neruol Sci [Suppl 6] $8: 7-120$
20. Carlesimo GA, Caltagirone C, Gainotti G, Nocentini U (1995) Batteria per la valutazione del deterioramento mentale: standardizzazione e affidabilità diagnostica nell'identificazione di pazienti affetti da sindrome demenziale. Arch Psicol Neurol Psichiatr 4:471488

21. Caltagirone C, Gainotti G, Masullo C, Micieli G (1979) Validity of some neuropsychological tests in the assessment of mental deterioration. Acta Psychiatr Scand $60: 50-56$

22. Wechsler D (1958) The measurements and appraisal of adult intelligence, 4th edn. Williams \& Wilkins, Baltimore

23. Hyman BT, Van Hoesen GW, Damasio AR (1990) Memory related neuronal system in Alzheimer's disease: an anatomic study. Neurology 40:17211730

24. Squire LR, Zola-Morgan S (1990) The medial temporal lobe memory system. Science 253:1390-1386

25. Perani D, Bressi S, Cappa SF, Vallar G, Alberoni M, Grassi F, Caltagirone C, Cipollotti L, Franeschi M, Lenzi GL, Fazio F (1993) Evidence of multiple memory systems in the human memory. Brain 116:903-919 